\title{
Methodological Paradigms of Social Philosophy: Boundaries and Possibilities in the Study of the Identification Process
}

\section{Yury Grigorievich Volkov}

\author{
Southern Federal University, Rostov-on-Don, Russian Federation \\ Email: infoippk@sfedu.ru
}

\section{Svetlana Igorevna Imgrunt}

Southern Federal University, Rostov-on-Don, Russian Federation

Alexandr Yurjevich Nechushkin

Southern Federal University, Rostov-on-Don, Russian Federation

Doi:10.5901/mjss.2015.v6n3s3p349

\begin{abstract}
Constructivist paradigm represents civil identification as a process of constructing of organized civil identity of the individual by the elites in a certain way, which is becoming an essential component of social development. Constructivism due to its inherent emphasis on procedural and variability makes it possible to study the multidimensional model of civic identification with the rapid changes in the stratification structure with simultaneous pluralization and transcoding cultural codes and public mentality shifts, which is characteristic of radically transforming societies. Socio-philosophical study of identity processes in the transformed Russian society based on constructivism suggests a methodological synthesis, which provides analysis of the influence of stratification and socio-structural factors such as the objective of the matrix to form a new common civil identity, as well as allows taking into account the socio-cultural and civilizational parameters Russia.
\end{abstract}

Keywords: identity, identification, constructivism, multivariate model studies, social inequality

\section{Introduction}

One of the key problems of the transforming Russian society is the identification crisis, which emerged in the 90s because of the rapid break-up of the former societal subsystem. Its immediate prerequisite was the refusal of the state from further maintenance and preservation of the Marxist mono-ideology, formerly being the state forming and the basis for socialization and social identity of the Russians. In addition, important prerequisites of the identification crisis were property and status stratification of society, the conflict of old and new socio-cultural values, a dramatic expansion of cultural exchange with Western society and the invasion of values and behaviours that have emerged in the Western cultural space. Finally, the revival of ethnic, cultural, and religious traditions in the past systematically pushed to the periphery by the Soviet society led to the actualization of cultural pluralism, which remained in a latent state for long time, which was a traumatic element for most people, accustomed to a uniform and consistent system of values.

All these factors combined have led to the emergence among the modern Russians of significant difficulties in attempting to identify themselves with the processes, structures, and values, offered by today's Russian society. First, stable social identification prevents instability and uncertainty of the Russian social reality, the constant and rapid changes that do not allow the identification process at this stage become fixed. Secondly, the presence in the community of strongly differing value orientations and worldview groups and expressing their interest's public figures creates an atmosphere of polarized and intense social and cultural space, in which it is extremely difficult for a person to find clear civil identification. Third, nostalgic Soviet sentiments remain very strong, which, for example, resulted in the identification of many of the respondents to the researches as the "Soviet citizens" and this, of course, prevents the implementation of the identification in the present.

Since civil identification is very important in terms of the integration of society, strengthening both vertical and horizontal social ties, it is one of the main components of self-preservation and development of socio-cultural space with its specific organization. This is particularly important in conditions of advancing globalization on national communities, 
erasing or distorting local identity. Impact of globalization on identity processes is expressed in particular in the "completion" of complex hybrid forms of identity, accompanied by a loss of some essential components of the national culture.

All of this suggests the relevance of referring to the social and philosophical research process, civil identification of the Russians in conditions of a transforming society, diversity, and intensity of social inequalities, challenges, and risks of globalization.

\section{Literature Review}

In recent decades, the problems of identity and identification have rapidly moved to the centre of research interest of sociologists, philosophers, psychologists, political scientists, although still relatively recently those terms in the national socio-humanitarian ideas were used only occasionally. The popularity of these concepts has increased primarily because of the failure of the exclusive position of the formation approach and the emergence of the possibility to build a study based on different methodologies and paradigms.

In this sense, of course, we shall recognize that the very terminology was developed not only in the European thinking space, but it is Western thinkers, who were the initiators of addressing the problems of identity. Starting with the philosophers of classical and post-classical periods, who raised the question of the oneness of the individual, that is, literally, "identity", and represented by the founders of psychoanalysis - S. Freud, who used the term as a synonym for the conscious ego (Freud, 2010), and K. Jung, who considered identity as a product of the individuation process in the mainstream of religious traditions, European thinkers put and solved the problem of the formation of self-identical human individuality in its relationship with the deep content of the individual (unconscious) and the image of the Other (social reality). The beginning of the twentieth century in European philosophy was marked by the so-called "Anthropological turn" from epistemologically oriented theory to the study of holistic vision of the human person with its depths and mysteries. If the prerequisites for the anthropological turn can be considered already in Fichte, Schelling, and Hegel, then the texts by Schopenhauer, F. Nietzsche, $\mathrm{Cl}$. Brentano, A. Bergson, and other philosophers of that period laid a strong foundation of philosophical investigation of human identity.

Existentialist thinkers continued this analysis, and made the actual identity as the centre of their attention. $\mathrm{M}$. Heidegger (Heidegger, 2010), seeing it because of consciousness temporalisation, realizing the presence at the world, J.P. Sartre (Sartre, 1946), who gave a subtle phenomenological analysis of the relationship between the "I" and the Other as a basis of the social world in which a human being lives and acts, and G. Marseille, who described the two models of personal identity - egocentric and theocentric, made an invaluable contribution to the philosophical study of the identification process. From the point of view of phenomenology by E. Husserl (Husserl, 1913), phenomenological sociology and human identification take place in the context of the life-world and is limited by the scope of its horizons.

In sociology, psychology, traditionology, the issues of personal and social identity are considered in a somewhat different angle. The subject field of these disciplines represents identity and identification as not personally and ontologically, but as socially constructed phenomena - from the sociological substantialism by K. Marx, defining the essence of a human being as "the aggregate of all social relations", and to the symbolic interactionism by I. Goffmann (Goffman, 1959), where the identification is situational in nature and takes place in the context of the changing role of interactions. In the interactionism by J. Mead (Mead, 1925) and C. Cooley (Cooley, 1902), the term of "identity" is replaced by the concept of semantically identical term of "self". Self means stable core personality, formed in the process of social interaction and completely owing its existence to view and evaluation of the Other - a partner in the social game (see, for example, the concept developed by Charles Cooley named "mirror self"). The junction of sociology and psychology was the source for emerging of the concept of identity by E. Erickson, G. Tajfel and other researchers, who allocated irreducible to each other its individual and social levels. These concepts emphasize the procedural, complex, and multi-layered nature of identifying and defining role in this process of the social environment.

Modern macro-sociological theory also concerns the problems of identitylidentification, mainly in aspects related to the growth of socio-cultural uncertainty and complexity of the identification process in these conditions, as well as the impact of globalization on the specificity of identification and identity of the individual in local communities. Thus, according to S. Bauman (Bauman, 2011), identification search is now a key social problem, as stable identity landmarks, offered by the tradition, are lost, and at the same time, its shape and structure of the social self are lost as well, finding amorphous and fluidity. 


\section{Methodology}

Theoretical and methodological basis of the study is built on the paradigm of constructivism in which any identity is seen as a product of social construction, and the process of its formation - identification - can be studied in detail in terms of identifying the impact of various facilitating and impeding factors, including the presence in the community of this or that types of inequalities. In addition, the article is based on the work and ideas of philosophers and representatives of other areas of socio-humanitarian knowledge, who studied civil identification as a process of directional influence of society on the individual. These include: traditionalists: Sh. Eisenstadt, E. Shils, who considered the identification processes as a necessary component of ethnic and cultural dynamics; founder of the sociocultural approach P. A. Sorokin, who offered an effective model for study the influence factors of the social order on the formation of cultural orientations of the person; sociologists Zaslavskaya (Zaslavskaya, 2002), M. Gorshkov (Gorshkov, 2011), N. Tikhonova (Tikhonova, 2013), who traced the influence of stratification dynamics of the transforming Russian society on the formation of a new Russian identity; S. Bauman, who outlined the general direction generated by modern changes in the search for identity (Bauman, 2000). The paper used the methods of theoretical analysis of existing papers on the stated problem, and the method of generalization and extrapolation of the results.

\section{Results}

Social philosophy, in contrast to the more specific socio-humanitarian disciplines, considers the processes of personal and social identity based on their own methodological approaches that outline the location of identification processes in the whole structure of the person and describe their contents depending on the overall trends in the development of societies. Various philosophical paradigms such an interpretation can have their own specifics.

Classical German philosophy is known for the fact that the problem of identity was raised by Immanuel Kant, who believed that the actual centre of the construct of identity is in the transcendental subject, and whose freedom is represented by transcendent and not limited spatio-temporal framework, the basis of identity. As the rational ethics in the Kantian philosophy is a construct produced by freedom, identity is dependent solely on the free self-determination of the individual.

Marxist (formational, objectivist) paradigm of the society study and the activity approach in the treatment of personality formation have long served as a broad understanding of the methodological basis of the identification process. The semantic centre of this understanding is the known provision by $\mathrm{K}$. Marx on the absolute social and economic determinacy of the essence of personality and ineradicable objective pursuit of the individual to be like public priorities. Marx and his followers believe that there may be a significant difference between the self-identity of the individual, which can only be socially constructed by a subjective illusion, and "objective" social being, not depending on their preferences and individual choice. Perhaps this is why Marx's idea of identification now seems incomplete and superficial, because the actual process of identification extends to more features and aspects of human existence. Nevertheless, Marxist trend philosophy created a system of scientific concepts of the human person as a product of social conditions and formed a paradigm explaining intrapersonal processes of identification with social relations and patterns in terms of "alienation" and "converted form", etc. This understanding has been widely demanded by researchers of the Soviet period, who received findings of their ideas about the identification from the known Marx's provision on that the objective essence of a human being is a set of social relations and is manifested in purposeful activity.

Thus, the difference of the Marxist (formational) paradigm with regard to the identification of the research is in the search for an objective social bases of the process that cannot be realized by the individual in own subjective identification search. According to Marxist attitudes, the individuality has nothing that would not be due to its social class. In this sense, other parameters of identification are deprived of their significance and meaning: ethno-national, cultural, religious and other parameters.

Formal paradigm in social philosophy, developed by G. Simmel, treats identity as the individual's one, realizing their own through correlation with supra-individual unity (Simmel, 2010). Understanding of oneself, own "I" is born from the experience of own assignment to a certain community, ethnic group, nation, generation, religious community, professional community, etc. In this case, the identification is carried out through identification with the characteristics of other individuals, but this identification happens in a way it that does not allow the individual to have individuality collapsed.

Simmel argues, however, that the social structure forms a stable form, beyond which the individual "l" cannot go (Ritzer, 2008). Individual identification occurs within social circles, but what is of fundamental importance that distinguishes the Marxist position from Simmel's position, includes not only the adoption of individual socio-approved 
models, but also a manifestation of their independence from the social group regulation. The narrowness of the social circle of the person promotes its greater social inclusion and therefore increases the risk of loss of individual freedom. Small social circles, such as family, at the same time absorb the personality and force it to resist absorption by broader social communities. Thus, according to Simmel, the source for identification is personality with its individual psychology, while scope and means of implementation includes social structures and historical factors.

Similarly to G. Simmel, E. Durkheim is a significant figure and one of the founders of the sociology science, and one of the classics of European social and philosophical thought. In the functionalist paradigm established by Durkheim, personal identification itself is one of the social functions and performs a number of social functions. The most important of these functions is integrative one, combining the individual into a collective whole, as well as socialization, contributing to the formation of the individual in the value perceptions of the community. Durkheim treats society as a totality, a unified collective morality, and common collective consciousness. The basis of this association, according to Durkheim, initially is in the religion. It is it to create and implement the consciousness of individuals of value-regulatory submission, subordinating individual will by values and goals of the social whole. Like Marx, Durkheim sees a distinction between objective and subjective cuts of the identification processes. If identification is experienced subjectively by individuals as a symbolic or value and moral identification with one or other sacred designs and concepts associated with the group, the objective identification process has its roots in the social nature and is a mechanism of subordination of individual consciousness to the collective consciousness.

Therefore, if we follow the theories by Simmel and Durkheim, it is possible to derive some basic characteristics and principles of identification. Firstly, the identification has a distinct emotional and sensual nature. It is not simply being aware of the individual's ability to "try on" the mask of "another" person and to adopt the role performed in the social group, but also an unconscious desire to possess values and adherence to rules and compliance with the taboos, allowing the individual to feel own "I" as a part of this society. Secondly, the desire of the individual to have any social values is also opposed to personal sense of social belonging. Thirdly, sharing the value system of any one group, the individual is in opposition to another group. Fourthly, according to Simmel, if the subject of the identification is the authority (personal or authority of the whole group or collective as a whole), it becomes evident the need for a sense of social belonging, i.e. the individual must make some effort to ensure absorbing and learning the rules and symbols of the hosting community. All these will help to understand further the mechanisms of rational relationships within the community and, ultimately, to build a system of generalized collective representations shared by all members of the group taken.

Psychoanalytic paradigm has brought a lot of valuable information to the understanding of personal and social identity. It should be noted that in this context, we consider the psychoanalytic concept as going beyond the concretepsychological conception of a human being: psychoanalysis may be rightly regarded as an independent philosophical paradigm, not only as a method of psychological research and psychotherapy. According to S. Freud, identification processes are mechanisms for reducing existential entropy, required for the normal life of the individual. Freud compares the desire of an "ordinary" or a "weak" person to imitate the leader or leaders of a group with an attempt of a child to copy the demeanour and behavioural models of parents, using these measures to learn how to deal with the fear of reality. Further research in this field and the publication of a number of new facts on this issue led to a deep and thorough study of the "method". The concept of identification was transferred from the scope of psychoanalytic concepts in other branches of knowledge and acquired a different form. Thus, many researcher refer to the following perception as a reference presentation of identification: the basic need of a human being as a potentially developing member of any society is to look for some personalized samples (having a certain set of qualities), and to imitate them. Classification of identification types takes place in conjunction with the classification of current social movements, and movements of communities, groups, and social strata; charismatic leaders also play an important role.

According to Freud's theory, the identification is first matching parental behavioural model, and then, as the personality grows older, it is transferred to the higher levels of social relations. Moreover, the identification is considered here as a predominantly unconscious process of imitation. This process reflects the desire of the individual to protect itself from the pressure of instincts and to form a personal-moral authority called superego through the emulation of those or other qualities of the "leader" (in this case the mother acts as the leader).

Separating from Freud's concept, the modern versionable psychoanalysis gives slightly modified interpretation of identification. This mechanism acts here as a psychological defence of the individual "I" against some objects, which theoretically may be the threat for the subject. Such object identification may be both real and ideal people (examples may include characters of artworks and mass culture). The identification model may also be a person with respect to which the individual is experiencing positive or negative emotions.

By the mid-twentieth century, the experts in the field of psychoanalytic theory identified such concepts as self, the 
narcissistic core of the personality, and intra-psychic structure of personality. The researchers also concluded as follows: the individual needs to shape the holistic "I", by which the individual can achieve personal fulfilment. Holistic "I" plays an important role for the interaction of the individual and its social environment. These discoveries in the field of psychoanalysis allow deeper insight into the subject of the identification of an individual in a social group.

Unique approach in the framework of psychoanalytic philosophy of a human being and society to understand the proposed identification C.-G. Jung. In his view, the identification of the person is its individuation, i.e. the integration of disparate elements of the identity into a coherent construction by practices of identity formation, established in traditional religions. In order to find a place in society, a person shall identify oneself with archetypal model, being the base of the sacred cultural tradition in which the person is brought up.

The mental level is the place for the assimilation of certain spiritual values, attitudes and behaviour models, making up the visible manifestations of identity subsequently affecting the lifestyle and individual behaviour (Hothersall, 2004). According to M. Blok, this complex can be described as "psychological furnishing" of the identity, M. Eliade describes it as "symbolic paradigms", P. Ricker - as the "dominant metaforms", S. Freud uses the term of "archaic remnants", and C. Jung - a well-known term of the "archetypes", "...the presence of which - according to the psychologist - is not explained by the individual's own life, while follows from the primitive congenital and inherited sources of the human mind" (Jung, 1991).

In the basic philosophical concepts, post-structuralism focuses on the dual nature of the discourse of identity. In the first place, it focuses on the internal contradictions between exaltation and self-abasement, typical for almost all models of identity. In this context, the base of binary oppositions in the structure of identity can be found in the personalization of collective identity and in the asked questions about the meaning of the existence of a particular individual or a group of individuals, referred to as an ethnic group. In modern society, the last question becomes one of the key and frequently asked ones, but remains without a clear answer. Identity does not exist as something complete and finalised; rather it can be characterized as a permanent search for some kind of integrity that often and remains unattained. Totality of identity is possible only in the ideological constructs created for manipulating the mass consciousness, whereas in the social philosophy of the concept of identity is never considered as a complete or full.

Over time, the study went beyond the identification of the psychoanalytic concept and became the object of study for behaviourism, which also can be seen not only in the narrow psychological, but also in the broader socio-philosophical and philosophical-anthropological sense. Behaviourism as philosophy sees the human identity as a set of behavioural responses that occur uniquely in response to certain environmental stimuli of physical or social environment.

According to some researchers-behaviourists (N. Miller, O. Maurer, D. Dollard), identification is the statement of the second, socially oriented, identity. This is the process of establishing certain regulated relations within which behaviours are shared by both parties. Identification generates dependence and affection for obtaining individual readymade forms of behaviour. Behavioural researchers (e.g. H. Levine, E. Maccoby) note that identification is achieved by reinforcement, imitation, generalization and monitoring the use of behavioural models. It is behaviourism to start considering not only the biological and psychological, but also socially important aspects of identification. Recognition of the conscious element in the process of identifying as prevailing over all others is the undisputed achievement of behaviourists.

The framework of the cognitivist (phenomenological) paradigm considers personal and social identity at the level of cognitive processes that take place on the conscious (but not on the unconscious, as adherents of the psychoanalytic concept believed) level. Thus, thanks to the cognitivist research by J. Turner (Turner, 1985) and H. Tajfel (Tajfel, 1982), identity received a description through the categorization processes, involving the subject itself and its surrounding individuals. Social categorization is the cognitive division onto groups, which helps to form group favouritism. It is used by individuals in social interaction, with the help of which the individual is able to structure the remembrance of their social environment and to issue guidelines and values system, occupying a definite place in the social group of any society etc. Individual's perception of itself (identity) is divided into two plans. The first exists within the unique personal characteristics, i. e. personal identity. The second is the self-determination within the framework of membership to a particular social category, i.e. social identity. Both options of self-categorization are possible only in the realizing of an individual as a unique member of a society, followed by thinking about its place and its role in the framework of a social category. The individual takes an active role in the selection of mechanisms that can assist the process of selfdetermination, to be relevant and useful in a given situation and environment. The above-mentioned ideas by Tajfel and Turner (Tajfel, Turner, 1986) became the basis of the researches by the domestic researchers - T. V. Rumyantseva and N. L. Ivanova, who developed the cognitive models of identity.

The methodology of philosophical pragmatism has also added a number of valuable ideas and concepts in the study of the processes of identification, caught substandard in relation to traditional approaches and at the same time 
related with respect to certain provisions and postulates of cognitive sociology. Among these ideas is the appeal to the analysis of language and cultural issues, the study of the internal structures of the individual and social reality simulation, and many others. A pragmatic concept of social identity and social identity was laid by W. James (James, 2010). According to the theory by James, the individual thinks of itself at different levels. The first level is personal, on which personal self-identity is formed. The second level is social, on which the diversity of social images for "I" of the individual is formed. Both levels are tied to the socio-practical and individual practical purposes. They are manifested in various forms of individual-personal and collective experience.

Thus, having considered a number of methodological paradigms of social philosophy in terms of their specificity and opportunities in the study of the phenomenon of identification at the individual and collective levels, we can conclude that the identification is generally regarded as the process of forming socially significant qualities by which the individual is able to realize themselves within a social group.

The Russian philosophical discourse emphasis has traditionally been focused on intersubjectivity and dialogue of the identification processes. Russian philosophers of the second half of XIX - early XX centuries based their researches on the dichotomy of "I-You", in other words - "I-World", "I-Environment", "I-Context". Moreover, when studying the interaction of the individual with the environment, they paid special influence on the sensory aspects of life, such as spiritual experiences and the very notion of the human soul.

The ideas of the domestic philosophers go back to the intuitions and the Great Russian literature, particularly to the works by Dostoevsky, who raised questions about the ontology of the individual, its attitude, and interaction with the environment and people surrounding the person. The papers by Berdyaev and G. Shpet approve the need for a synthesis of theoretical (scientific theory) and artistic approaches and types of perception and assimilation of information. $\mathrm{L}$. Karsavin was the first to bring up the idea of the unity of personality and cognitive knowable reality. Soviet philosophers and humanists (D. Likhachev, Yu Lotman, M. Bakhtin, and B. Porshnev) developed the idea that the specific spiritual and mental processes inherent in a human being, appear only because of human interaction.

The concept by Russian social philosopher and sociologist, Pitirim Sorokin, focuses on the relationship between social order and its axiological foundations, through which the system of relations in society is regulated (Lawrence, 2001). In this context, the identity models appear as a basis for preserving the value system of society and its cultural component. The process of self-identification by the individual with a certain cultural system is defined as the personality identification concept.

Accordingly, identifying with a particular culture, the individual shares the values, and behaviours of coordinates, which lay within a given culture. Preservation of identity implies, thus, the preservation and reproduction of the respective value and attitudinal and behavioural settings of a certain culture. At the same time, the identity may undergo some changes in the process of social transformation, as evidenced by numerous historical examples.

The concept by Pierre Bourdieu sees culture in the context of the study of the formation of the social system. Respectively, the interdependence of culture identity is analysed from the perspective of influences on social processes (Bourdieu, 1990). N. Luhmann understood identification as a fundamental component of autopoiesis, which serves to strengthen the social system (Luhmann, 1995).

Reproduction of identity is carried in the society through cultural continuity mechanisms, which facilitate the transmission of socio-cultural values and traditions from generation to generation. At the same time, social transformation processes may contribute to the crisis in the field of value-philosophical orientations, entailing a devaluation of values and identity crisis.

The need to preserve the foundations of identity must always be taken into account in the process of any social and political changes, as the identity crisis and vacuum may have very negative consequences for the social system. If identity is not preserved, the system of intergenerational communication, broadcasting sociocultural experience is interrupted. Respectively, socio-cultural foundation of existence of a particular social system is lost.

It is in the process of socio-cultural communication and reproduction of identity for the individual to learn certain value orientations, patterns of behaviour and thinking, allowing identifying with specific cultural environment. Lack of mechanisms for broadcasting sociocultural experience destroys thus not only ethnic and civic identity, but the identity of the person, preventing the absorption of values and, ultimately, reproducing "people without identity", most of which are experiencing serious ideological crisis.

Constructivist direction in the methodology of social thought is considering the establishment of both individual and collective, including macro-social identity as a process of constructing meanings, values, and behaviours, laid in a person with a view to the preservation and maintenance of a particular social system. Within this framework, the identification process at any level appears directed and controlled, flexible and changeable, unlike hard schematics objectivist methodologies. 
Thus, through a set of identity and the collective unconscious, the specific mentality is formed for a particular ethnic group, geographically localized and differing from neighbouring ethnic groups for not only the language features or material culture, but also for the traditions, values, and mentality. That is, identity has underneath both social (social and cultural) and biopsychic bases, broadcasting from generation to generation as a distinct socio-cultural code. The latter forms the foundation upon which representations of the possible styles, norms, and rules of conduct, rooted in ethnic identity, rest. In other words, socio-cultural code passes the knowledge on the specific positive and negative social phenomena, ideas, and behavioural orientations. Moreover, thanks to it, in the end, there is the preservation and transmission of what we call the national/ethnic identity.

\section{Discussion}

Socio-philosophical study of identification within the objectivist methodological paradigm involves secondary identification processes, their formation as a "superstructure" of social structures, the nature of which is determined by social class and stratification affiliation. In the context of the constructivist paradigm, the social and philosophical study of identity focuses on identifying the nature of identity as a construct of a deliberate strategy by the ruling elites of integration and consolidation of society.

More recent social and philosophical concepts consider the process of identification from the perspective of social and cultural codes, which are incorporated in the individual specific social practices. Turning to the post-modern research methodology, the identification processes study is able to analyse the multidimensional factors and determinations of identity in all their diversity, which is especially important in today's social environment characterized by permanent change and global transformation processes.

The main drawback of the objectivist approach to the identification process study is because the theories based on it pay no sufficient attention to the aggregate social roles played by the subject. In constructivism, on the contrary, social identity is regarded primarily as a forming for a long period of history and ever changing ideological construct that does not have an objective basis. Both points of view are the extremes, which shall not be applied as they are.

However, it should be noted that the presence of a significant range of scientific and philosophical works devoted to the problem of identity, including civil identification, does not mean the exhaustion of the topic for further research. After all, one cannot deny the obvious fact that the existing inequality and heterogeneity contribute to accentuation of differences and disputes between citizens and hinder the development of their conscious understanding of the unity and the common interests of all the Russians.

\section{References}

Bauman, Z. (2011).Culture in a Liquid Modern World. Cambridge: Polity. pp. 18-32.

Bauman, Z. (2000).Liquid Modernity. Cambridge: Polity.

Bourdieu, P. 91990). Structures, habitus, practices. In P. Bourdieu, The logic of practice (pp. 52-79). Stanford, CA: Stanford University Press. Bourdieu. (p. 54).

Cooley, Ch. (1902) Human Nature and the Social Order. New York: Scribner's. (pp. 179-185). Retrieved from: http://www.cardiff.ac.uk /socsi/undergraduate/introsoc/social3.html

Freud, S. (2010).Psychoanalytic studies. Comp. by D. I. Donskoy, V. F. Kruglyanskiy. Minsk: Popurri.

Giddens, A. (1991). Modernity and Self-Identity. Self and Society in the Late Modern Age. Cambridge, Polity Press.

Giddens, A. (1991). Consequences of Modernity. Standford, University Press.

Goffman, E. (1959). The Presentation of Self in Everyday Life. Edinburdh: University of Edinburgh Social Sciences Research Centre.

Gorshkov, (2011) M. K. Russian society as it is: (experience of sociological diagnosis). M.: Novyi Khronograph.

Gorshkov M. K. \& Tikhonova N. E. (2013). Sociocultural consolidation factors of Russian society. Institute of Sociology of the Russian Academy of Sciences. M.: Institute of sociology RAS.

Heidegger, M. (2010). Being and Time. Albaniae: State University of New York Press.

Hothersall, D. (2004). "History of Psychology", 4th ed., NY: Mcgraw-Hill. (p. 290).

Husserl, E. (1913). Ideen zu einer reinen Phänomenologie und phänomenologischen Philosophie: Buch 1, Allgemeine Einführung in die reine Phänomenologie. Halle/Saale. (pp.108-118) Retrieved from: http://www.freidok.uni-freiburg.de/volltexte/5973/

James, W. (2010). The psychology of faith. Interactionism in American sociology and social psychology, the first half of the twentieth century: Collection of translations. M.: The Russian Academy of Sciences. The Institute of Scientific Information for Social Sciences. Centre for Social Science and Information Studies. (p. 29-69).

Jung, K. G. (1991).Archetype and symbol. Moscow: Renessans. (P. 64).

Lawrence, T. N. (2001). Science, politics and moral activism: Sorokin's integralism reconsidered. Return of Pitirim Sorokin. M.: International Kondratieff foundation. (P. 217-237). 
Luhman, N. (1995). Social Systems. Stanford: Stanford University Press.

Mead, G. (1925). The Genesis of the Self and Social Control. International Journal of Ethics 35. (P. 251-277). Retrieved from: http://www.brocku.ca/MeadProject/Mead/pubs/Mead_1925.html

Ritzer, G. (2008).Sociological Theory. New York, McGraw-Hill.

Sartre, J-P. (1946). Existentialism Is a Humanism. Retrieved from: https://www.marxists.org/reference/archive/sartre/works/exist/sartre. $\mathrm{htm}$

Simmel, G. (20100. The View of Life: Four Metaphysical Essays with Journal Aphorisms. Chicago: University of Chicago Press. (Pp. 7590).

Tajfel, H. (1982).Social identity and intergroup relations. P.: Maison des Sciences de 1'Homme and Cambridge: Univ. Press.

Tajfel H. \& Turner J. (1986). The social identity theory of intergroup behaviour. Psychology of Intergroup Relations. 2nd edn. Chi.: Nelson-Hall.

Turner, J. (1985). Social categorization and the self-concept: a social cognitive theory of group behaviour. Advances in Group Processes. V. 2. (P. 77-121).

Zaslavskaya, T. I. (2002). Societal transformation of Russian society: Activity-block concept. M.: Delo. 